$01 ; 11$

\title{
Экспериментальное исследование синхронизации неидентичных нейроподобных осцилляторов с адаптивной запаздывающей связью
}

\author{
() В.И. Пономаренко ${ }^{1-3}$, Д.Д. Кульминский ${ }^{1-3}$, М.Д. Прохоров ${ }^{1,2, \text { ฯ }}$
}

${ }^{1}$ Саратовский филиал Института радиотехники и электроники им. В.А. Котельникова РАН, Саратов, Россия

${ }^{2}$ Саратовский государственный технический университет им. Гагарина Ю.А., Саратов, Россия

${ }^{3}$ Саратовский национальный исследовательский государственный университет им. Н.Г. Чернышевского, Саратов, Россия

"E-mail: mdprokhorov@yandex.ru

\section{Поступило в Редакцию 4 мая 2018 г.}

Построена радиофизическая модель двух автогенераторов ФитцХью-Нагумо, связанных запаздывающей связью. В модели экспериментально реализована возможность введения как постоянной, так и адаптивной связи между генераторами. Показано, что использование адаптивной связи позволяет перейти от противофазной синхронизации неидентичных генераторов к их синфазной синхронизации.

DOI: 10.21883/PJTF.2018.17.46565.17366

Синхронизация взаимодействующих автоколебательных систем фундаментальное явление, наблюдаемое в системах различной природы [1]. Способность к синхронизации присуща многим живым системам и объектам, причем в одних случаях синхронизация необходима для жизнедеятельности организма, например для осуществления моторных функций [2] и функционирования внутренних органов $[3,4]$, а в других случаях является патологией, например при синхронизации нейронов головного мозга, приводящей к эпилепсии [5] и болезни Паркинсона [6]. Задача управления синхронизацией осцилляторных систем актуальна для различных научных дисциплин и привлекает внимание многих исследователей [7-9]. Пре- 
имущественно эта задача рассматривалась для случая идентичных осцилляторов. Однако на практике взаимодействующие осцилляторы, как правило, различаются по параметрам и, следовательно, имеют разные частоты и амплитуды колебаний. Расстройка параметров осцилляторов препятствует их синхронизации [10]. В последние годы большое распространение получили адаптивные методы управления синхронизацией, параметры которых меняются во времени [11-13]. Такие методы позволяют расширить границы синхронизации неидентичных осцилляторов за счет введения адаптивной связи между ними.

В настоящей работе экспериментально исследована синхронизация двух неидентичных нейроподобных осцилляторов, описываемых уравнениями ФитцХью-Нагумо [14], взаимно связанных запаздывающей связью. Рассмотрен случай, когда сила связи является постоянной, а также случай адаптивной связи. Впервые экспериментально показано, что введение адаптивной связи позволяет увеличить область синфазной синхронизации в пространстве управляющих параметров исследуемых систем.

Рассмотрим две взаимно связанные системы ФитцХью-Нагумо, модельные уравнения которых имеют следующий вид [14]:

$$
\begin{gathered}
\varepsilon \frac{d u_{1}(t)}{d t}=u_{1}(t)-\frac{u_{1}^{3}(t)}{3}-v_{1}(t)+C\left(u_{2}(t-\tau)-u_{1}(t)\right), \\
\frac{d v_{1}(t)}{d t}=u_{1}(t)+a_{1}, \\
\varepsilon \frac{d u_{2}(t)}{d t}=u_{2}(t)-\frac{u_{2}^{3}(t)}{3}-v_{2}(t)+C\left(u_{1}(t-\tau)-u_{2}(t)\right), \\
\frac{d v_{2}(t)}{d t}=u_{2}(t)+a_{2},
\end{gathered}
$$

где $u_{1,2}(t)$ и $v_{1,2}(t)$ - динамические переменные первой и второй системы, $a_{1,2}$ - управляющие параметры, $\varepsilon-$ параметр соотношения временны́х масштабов, $\tau$ - запаздывание в связи, $C$ - коэффициент связи. Для экспериментального исследования системы (1) нами была построена оригинальная радиотехническая установка, использующая идеологию аналогового моделирования. Блок-схема этой установки представлена на рис. 1 .

Письма в ЖТФ, 2018, том 44, вып. 17 


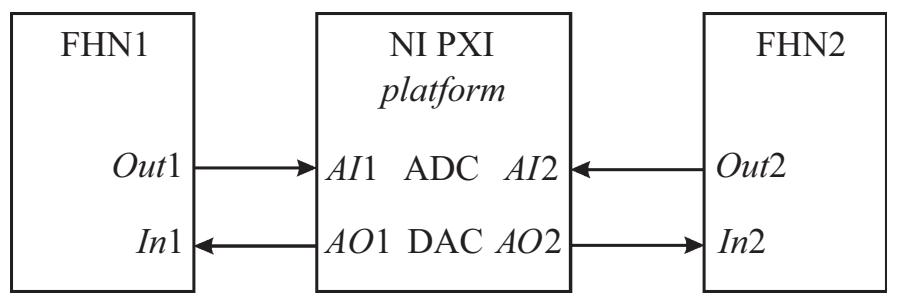

Pис. 1. Блок-схема экспериментальной установки. FHN1 и FHN2 - генераторы ФитцХью-Нагумо; Out 1 и Out 2 - выходные сигналы генераторов, соответствующие переменным $u_{1}(t)$ и $u_{2}(t) ; \operatorname{In} 1$ и $\operatorname{In} 2$ - входы воздействия на генераторы; ADC - аналого-цифровой преобразователь; DAC - цифроаналоговый преобразователь; $A I 1$ и $A I 2$ - аналоговые входы АЦП платформы NI PXI; $A O 1$ и $A O 2$ - аналоговые выходы ЦАП.

Для осуществления связи между генераторами ФитцХью-Нагумо, принципиальные схемы которых мы здесь не приводим, была использована платформа National Instruments, включающая в себя шасси, контроллер, блок аналогового ввода и блок вывода данных. Сигналы $u_{1}(t)$ и $u_{2}(t)$ с выходов Out 1 и Out2 генераторов FHN1 и FHN2 соответственно подаются на входы $A I 1$ и $A I 2$ цифро-аналогового преобразователя (АЦП) и с помощью программы на LabView оцифровываются с частотой $f=30 \mathrm{kHz}$ для дальнейшей обработки. Затем программным образом проводится нелинейное преобразование сигналов $u_{1}(t)$ и $u_{2}(t)$ и формируются сигналы $C\left(u_{2}(t-\tau)-u_{1}(t)\right)$ и $C\left(u_{1}(t-\tau)-u_{2}(t)\right)$, отвечающие за связь генераторов, которые с выходов $A O 1$ и $A O 2$ цифро-аналогового преобразователя (ЦАП) подаются в качестве управляющего воздействия на входы In 1 и In 2 первого и второго генератора соответственно. Таким образом, экспериментальная установка позволяет обеспечить нужный вид связи двух автогенераторов.

При неидентичности генераторов (1) их полная синхронизация в виде $\left(u_{1}, v_{1}\right)=\left(u_{2}, v_{2}\right)$ недостижима в полной мере, но возможна ситуация, при которой колебания обеих систем очень близки между собой. Такая ситуация соответствует синфазной синхронизации генераторов, при которой сдвиг фаз между их почти одинаковыми колебаниями равен нулю.

Письма в ЖТФ, 2018, том 44, вып. 17 

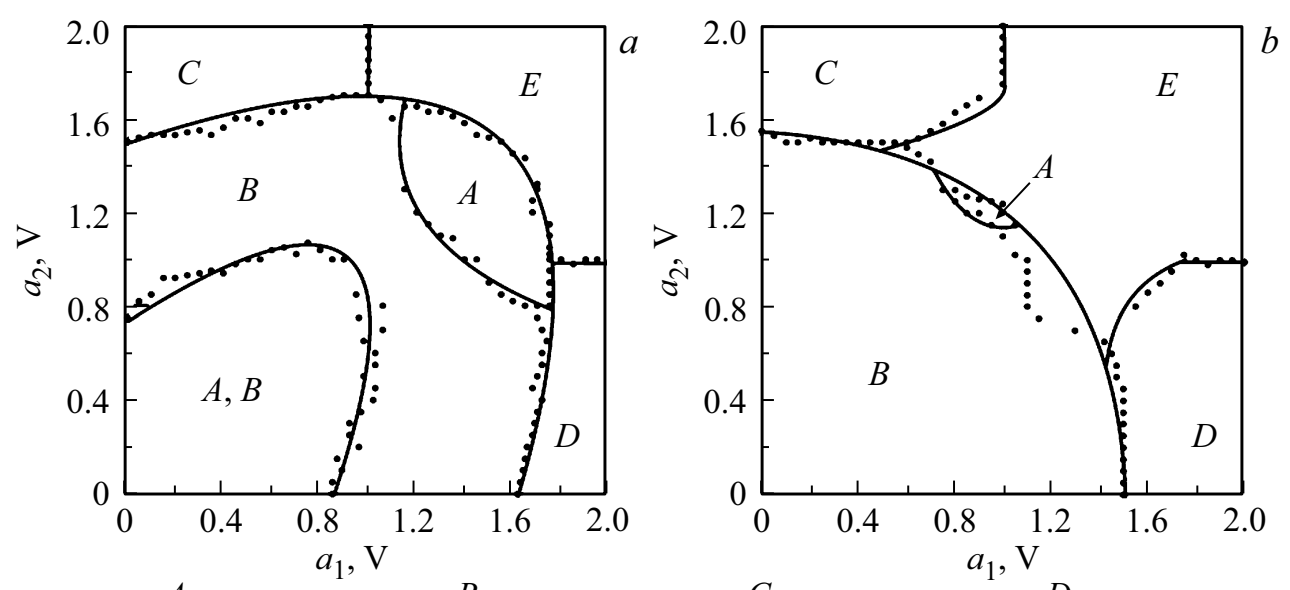
ФитџХью-Нагумо при постоянной запаздываюшей связи $(a)$ и адаптивной запаздываюшей связи $(b)$. Заглавными буквами обозначены области различных колебательных режимов. $c$ - временнб́е реализации $u_{1}(t)$ (жирные линии) и $u_{2}(t)$ (тонкие линии) в областях $A, B, C, D, E$. 
Нами экспериментально исследована динамика связанной системы (1) при различных коэффициентах связи $C$ и вариации управляющих параметров $a_{1}$ и $a_{2}$. На рис. 2, $a$ представлено разбиение плоскости параметров $\left(a_{1}, a_{2}\right)$ на области характерных колебательных режимов при $\varepsilon=0.1, \tau=7 \mathrm{~ms}$ и постоянном коэффициенте связи $C=3$. Экспериментально определенные границы переходов между режимами отмечены точками, через которые для наглядности проведены сплошные линии. В области $A$ наблюдается противофазный режим колебаний, при котором колебания первого и второго генераторов очень похожи, но сдвинуты по фазе на величину $\pi$. Область $B$ соответствует синфазному режиму. На рис. 2, $c$ приведены временны́е реализации колебаний переменных $u_{1}(t)$ и $u_{2}(t)$ в областях, отмеченных на рис. 2, $a, b$ заглавными буквами. В области $C$ первый генератор находится в возбудимом режиме, а второй - в колебательном режиме. В области $D$ имеет место обратная ситуация, при которой первый генератор находится в колебательном режиме, а второй в возбудимом (рис. 2,c). В области $E$ оба генератора находятся в состоянии устойчивого равновесия. Следует отметить, что в области, обозначенной как $A, B$ на рис. $2, a$, существует бистабильность, при которой в зависимости от начальных условий в связанной системе могут наблюдаться или противофазные, или синфазные колебания.

Рассмотрим теперь на той же экспериментальной установке случай адаптивной запаздывающей связи между двумя генераторами. Адаптивная связь имеет вид, который обеспечивает синфазную синхронизацию генераторов. При этом коэффициент связи $C$ в системе (1) не является константой, а изменяется по адаптивному закону, предложенному в работе [14]:

$$
C_{1,2}(t)=C_{0}+\frac{2 \gamma}{\varepsilon}\left(u_{1,2}(t)-u_{2,1}(t)+a_{1,2}-a_{2,1}\right)\left(u_{1,2}(t)-u_{2,1}(t)\right),
$$

где $C_{0}-$ начальное значение коэффициента связи, $\gamma-$ параметр адаптивной связи, $C_{1}(t)$ и $C_{2}(t)$ определяют вид адаптивной связи для первого и второго генератора соответственно. При $\gamma=0$ получаем рассмотренный выше случай постоянной связи.

На рис. 2,b приведено разбиение экспериментальной плоскости параметров $\left(a_{1}, a_{2}\right)$ системы $(1)$ на области характерных колебательных режимов при $\varepsilon=0.1, \tau=7 \mathrm{~ms}$ и коэффициенте связи, из-

Письма в ЖТФ, 2018, том 44, вып. 17 


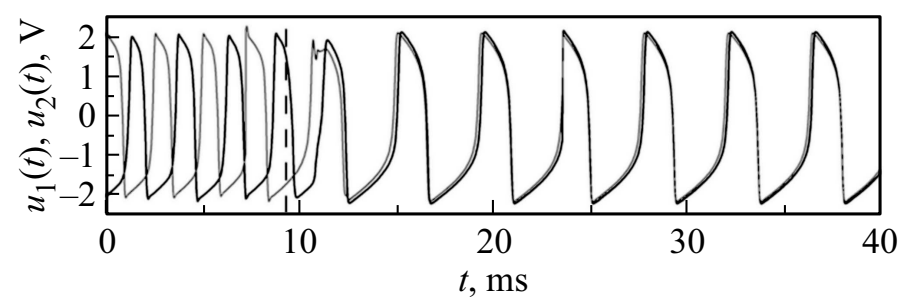

Рис. 3. Экспериментальные временны́е реализации $u_{1}(t)$ (жирные линии) и $u_{2}(t)$ (тонкие линии) при постоянной запаздывающей связи $(t<9.2 \mathrm{~ms})$ и адаптивной запаздывающей связи $(t \geqslant 9.2 \mathrm{~ms})$. Момент переключения связи с постоянной на адаптивную показан вертикальной штриховой линией.

меняющемся по адаптивному закону (2) с $C_{0}=3$ и $\gamma=0.02$. Из сравнения рис. $2, a$ и $b$ видно, что введение адаптивной связи привело к исчезновению противофазных режимов при малых значениях $a_{1}$ и $a_{2}$ и, как следствие, к исчезновению области бистабильности. Таким образом, использование адаптивной связи упрощает задачу достижения синфазной синхронизации неидентичных генераторов. Отметим, что при $\gamma<0.01$ на плоскости параметров $\left(a_{1}, a_{2}\right)$ сохраняется область бистабильности при малых $a_{1}$ и $a_{2}$.

Рассмотрим изменение динамики экспериментально реализованной системы (1) при переходе от постоянной запаздывающей связи к адаптивной. На рис. 3 показаны экспериментальные временнб́е реализации $u_{1}(t)$ и $u_{2}(t)$ при $a_{1}=0.5$ и $a_{2}=0.7$. При $t<9.2 \mathrm{~ms}$ генераторы связаны запаздывающей связью, величина которой остается постоянной, $C=3$. При этом генераторы демонстрируют противофазные колебания. В момент времени $t=9.2 \mathrm{~ms}$ происходит переключение связи с постоянной на адаптивную с параметрами $C_{0}=3$ и $\gamma=0.02$. После короткого переходного процесса, длительность которого составляет порядка одного характерного периода колебаний, в связанной системе устанавливается синфазный режим.

Итак, нами экспериментально исследована синхронизация неидентичных нейроподобных осцилляторов, которые связаны между собой адаптивной запаздывающей связью, и впервые построено разбиение 
плоскости управляющих параметров исследуемой системы на области существования различных характерных режимов колебаний. Показано, что введение адаптивной связи между неидентичными осцилляторами позволяет перейти от противофазной синхронизации к синфазной. Описанный подход может быть распространен на кольцевую систему, состоящую из большего числа связанных осцилляторов. Адаптивная связь способна обеспечить синфазную синхронизацию осцилляторов даже в случае большой расстройки их параметров и может оказаться перспективной в робототехнике при разработке центральных генераторов ритма [15], для которых важно обеспечить синхронизированность элементов в широкой области управляющих параметров.

Работа выполнена при поддержке Российского научного фонда (грант № 17-72-30003).

\section{Список литературы}

[1] Pikovsky A., Rosenblum M.I, Kurths J. Synchronization: a universal concept in nonlinear sciences. Cambridge: Cambridge University Press, 2001. 432 p. [Пиковский А.С., Розенблюм М.Г., Куртс Ю. Синхронизация: фундаментальное нелинейное явление. М.: Техносфера, 2003. 508 с.].

[2] Goulding M. // Nature Rev. Neurosci. 2009. V. 10. N 7. P. 507-518.

[3] Glass L. // Nature. 2001. V. 410. P. 277-284.

[4] Prokhorov M.D., Ponomarenko V.I., Gridnev V.I., Bodrov M.B., Bespyatov A.B. // Phys. Rev. E. 2003. V. 68. N 4. P. 041913.

[5] Blume W.T., Pillay N. // Epilepsia. 1985. V. 26. N 6. P. 636-641.

[6] Levy R., Hutchison W.D., Lozano A.M., Dostrovsky J.O. // J. Neurosci. 2000. V. 20. N 20. P. 7766-7775.

[7] Flunkert V., Yanchuk S., Dahms T., Schöll E. // Phys. Rev. Lett. 2010. V. 105. N 25. P. 254101.

[8] Клиньшов В.В., Некоркин В.И. // УФН. 2013. Т. 183. № 12. С. 1323-1336.

[9] Otto A., Radons G., Bachrathy D., Orosz G. // Phys. Rev. E. 2018. V. 97. N 1. P. 012311.

[10] Sun J., Bollt E.M., Nishikawa T. // Europhys. Lett. 2009. V. 85. N 6. P. 60011.

[11] Lehnert J., Hövel P., Selivanov A.A., Fradkov A.L., Schöll E. // Phys. Rev. E. 2014. V. 90. N 4. P. 042914.

[12] Makarov V.V., Koronovskii A.A., Maksimenko V.A., Hramov A.E., Moskalenko O.I., Buldu J.M., Boccaletti S. // Chaos Solitons Fractals. 2016. V. 84. P. 23-30.

2 Письма в ЖТФ, 2018, том 44, вып. 17 
[13] Масленников О.В., Некоркин В.И. // УФН. 2017. Т. 187. № 7. С. 745-756.

[14] Plotnikov S.A., Lehnert J., Fradkov A.L., Schöll E. // Int. J. Bifurcat. Chaos. 2016. V. 26. N 4. P. 1650058.

[15] Lodi M., Shilnikov A., Storace M. // IEEE Trans. Circuits Syst. I: Regular Papers. 2018. V. 65. N 3. P. 1028-1039. 